\title{
Evidencias sobre la segregación vertical en ciudades del sur de Europa. El caso de la ciudad de Málaga
}

\author{
Juan José Natera-Rivas, Remedios Larrubia-Vargas \\ y Susana Rosa Navarro-Rodríguez
}

\author{
Universidad de Málaga, España
}

\section{Resumen}

En la ciudad de Málaga el crecimiento de la inmigración ha supuesto un aumento de sus contingentes entre 2003 y 2013 de 133 por ciento, lo que ha incrementado el interés por su análisis. Los estudios realizados apuntan a que el grado de segregación social de los inmigrantes en los países del sur europeo no supera el de otras regiones, pero si indican la existencia de una fuerte precariedad habitacional. Bajo esta premisa nos planteamos si aunque no sea extrema la segregación residencial, la misma ha venido acompañada por un aumento de la segregación vertical. Tras efectuar un análisis sobre el estado de la cuestión, hemos caracterizado a los barrios objeto de estudio, y hemos procedido a la consecución de los datos, cuyo tratamiento nos ha permitido confirmar la constatación de dicha segregación.

Palabras clave: Segregación vertical, inmigración laboral, diferenciación residencial.

Abstract

Vertical segregation in southern european cities. the case of Malaga (Spain)

The city of Malaga has experienced a huge increase of foreigners between 2003 and 2013, but their levels of residential segregation are generally low, as occurs in many South European cities. Nonetheless, it is worth to study if this increase of foreigners has been accompanied by a rise of the levels of vertical segregation. Using data from the Padron Municipal de Habitantes, focused on eleven selected neighborhoods, we have been able to demonstrate that, in fact, vertical segregation is present among foreigners.

Key words: Vertical segregation, immigrants, residential differentiation. 


\section{INTRODUCCIÓN}

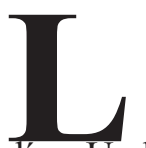

a inmigración extranjera se ha convertido en todo el territorio español en un importante factor demográfico y de transformación social desde las últimas décadas del siglo XX hasta nuestros días. Un hecho que se deriva de un cambio en las tendencias tradicionales de los movimientos migratorios y la consolidación de un nuevo modelo migratorio (Fernández, 2001). En España, tradicionalmente la inmigración procedente del exterior ha sido un flujo menor comparada con las salidas que históricamente se han producido; sin embargo, al tiempo que las salidas decrecían, las llegadas no han dejado de incrementarse década a década, acentuándose desde 1990 y continuando a lo largo de la primera década del siglo XXI. Pero junto a este cambio en el modelo migratorio también cabe hablar de un cambio en el patrón inmigratorio generado por el alto grado de diversidad que ha adquirido el fenómeno en la actualidad (Larrubia y Ocaña, 2014). De esta forma, se ha producido un debilitamiento de la corriente residencial y de consumo, característica de los flujos procedentes del norte y centro de Europa, y un reforzamiento simultáneo del patrón migratorio basado en la producción, con una definida vertiente laboral e integrado de forma mayoritaria por los naturales de los restantes continentes (Salvá, 2003).

El rápido crecimiento de estos flujos migratorios, que en el caso de la ciudad de Málaga ha supuesto un aumento de sus contingentes entre 2003 y 2013 en 133 por ciento, ha incrementado el interés por su análisis desde diversas perspectivas, entre las que destaca la distribución espacial de este colectivo atendiendo no sólo a sus pautas de distribución territorial, sino también a los procesos de segregación socioespacial debido a los intensos cambios socioeconómicos y culturales que llevan aparejados (Escolano, 2007). De esta forma el análisis de la segregación residencial de la población extranjera en ámbitos urbanos se ha convertido en una constante en el contexto europeo, especialmente en aquellos países que, al igual que España, han cambiado sus pautas migratorias de país emigrante a inmigrante, coincidiendo con el recorte en las prestaciones del Estado del Bienestar (Bayona, 2006), tras la generalización de la crisis económica.

Todos estos estudios establecen una comparación entre la situación de segregación de la población de los países del sur del continente europeo y los del norte y Norteamérica. En principio, el resultado que cabría esperar 
es un menor nivel de segregación en estos segundos, en virtud del menor recorte de las políticas de bienestar social y un mayor parque de viviendas sociales, si bien los trabajos ponen de manifiesto que el grado de segregación social de los inmigrantes en los países del sur europeo no es notablemente mayor que el de las zonas restantes, lo destacable es que conviven en una situación de fuerte precariedad habitacional (Arbaci y Malheiros, 2010).

Esta es una realidad que también se ha podido constatar en el municipio de Málaga. A lo largo de varios trabajos (Ocaña, 1998; Natera y Batista, 2012) se ha puesto de manifiesto que el incremento de extranjeros registrado en el municipio malagueño, con la única excepción de la población subsahariana, ha sido acompañado de un descenso de sus niveles de segregación residencial, medidos a través de índices de segregación. No obstante, también se ha mostrado cómo dicha disminución ha supuesto un aumento de la exclusión residencial. Los inmigrantes han tendido a concentrarse, en mayor medida que los españoles, en el parque habitacional en peores condiciones.

De cualquier manera, un aspecto no demasiado estudiado de los procesos de segregación y exclusión residencial es el de la segregación vertical. Prácticamente ausente en el corpus de literatura estadounidense, tampoco en el espacio europeo las investigaciones sobre la misma son demasiado numerosas, centrándose fundamentalmente en el ámbito espacial griego (Maloutas, 1993: Maloutas y Karadimitriou, 2001). En este contexto, cabe plantearse si la disminución de la segregación residencial ha venido acompañada por un aumento de la segregación vertical, esto es, si ha habido un aumento de la población extranjera residente en las plantas menos apetecibles. Por tanto el objetivo de nuestro trabajo trata de responder a la siguiente cuestión: ¿existe segregación vertical entre los inmigrantes laborales en Málaga?

En primer lugar realizaremos una aproximación general sobre el estado de la cuestión de la segregación residencial vertical, como marco conceptual de referencia de este trabajo, para acercarnos a continuación a la realidad física y sociodemográfica de los barrios objeto de análisis y, por último responder a la cuestión planteada.

\section{ESTADO DE LA CUESTIÓN: SEGREGACIÓN/DIFERENCIACIÓN RESIDENCIAL VERTICAL}

Dentro de la distribución espacial de la población en la ciudad, el acercamiento a sus características sociodemográficas ha sido un tema central en 
la investigación geográfica, porque la diferenciación residencial se convierte en un factor importante a la hora de explicar el comportamiento de los individuos, y porque el lugar de residencia es un claro determinante de las oportunidades vitales de la población. Así, desde principios del siglo pasado, gran parte de los estudios sobre la división social del espacio urbano se ha realizado en torno al concepto de la diferenciación/ segregación residencial.

En términos sociológicos, segregación significa la ausencia de interacción entre grupos sociales, e indica la existencia de diferencias o desigualdades dentro de un colectivo y la separación de los sujetos en distintas categorías valorativas. En términos geográficos se incide sobre la segregación residencial como modalidad específica de la segregación territorial en la que las categorías que separan a los individuos se refieren a su localización geográfica. En concreto hace referencia al grado por el que dos o más grupos viven separados unos de otros, en partes diferentes del entorno urbano, y se concreta en la existencia de variaciones en ciertas características entre los residentes de las distintas zonas de una misma localidad.

Los estudios sobre diferenciación residencial se han centrado básicamente en el estudio de la localización espacial de los grupos de población en la dimensión horizontal del espacio urbano; para ello se emplea todo un conjunto de instrumentos destinados a medir la diferenciación en cualquiera de sus dimensiones, o más recientemente, a indagar acerca de la aleatoriedad o no aleatoriedad de dichas distribuciones, empleando indicadores globales y locales de auto correlación espacial. ${ }^{1}$

Centrándonos en el contexto europeo, se han identificado pautas diferentes y niveles diferentes de diferenciación residencial entre ciudades de países de la Europa septentrional y central, y aquellas otras correspondientes a la Europa mediterránea (Arbaci, 2010).

Sin embargo, son comparativamente muy escasas las investigaciones centradas en la dimensión vertical del espacio urbano, esto es, centradas en la existencia de pautas de localización de los grupos sociales diferenciadas en altura. Prácticamente inexistentes en el contexto norteamericano, también en el europeo son muy escasas, habiéndose centrado básicamente en el espacio griego (Maloutas, 1993).

\footnotetext{
${ }^{1}$ Son muchos los investigadores que se han acercado a esta temática, entre los que podemos destacar: Shevky y Bell, 1955; White, 1983; Massey y Denton, 1988; Anselin, 1995. Ocaña, 1988; Leal, 1994; Maloutas,1993, Martori, 2004; Leontidou, 2009; Sabatini,1999; Rodríguez, 2001; Musterd y Deurloo, 2002; Malheiros, 2002; Fullaondo, 2007; Bayona, 2006, Bayona y López, 2011; Arbaci, 2010.
} 
De forma general para Europa, podemos indicar que los diferentes grupos sociales se han distribuido en la ciudad siguiendo patrones históricamente diferentes.

La altura de los edificios (cuando no existía ascensor), la dimensión de los hogares y sus dotaciones (agua, aseos, gas, etc.) fueron los primeros mecanismos de segregación.

Según este modelo, las clases de mayores recursos ocupaban las viviendas denominadas "principales" y el "entresuelo", en el primer y segundo piso. Mientras que las clases menos acomodadas iban situándose en las plantas altas, hasta las buhardillas, que eran ocupadas por los grupos menos solventes de la sociedad. Existía, por tanto, una relación inversa entre clase social y altura de la residencia. Circunstancia que denominamos diferenciación vertical porque hace referencia a una distribución desigual de los individuos, pero que también es segregación vertical porque tal diferenciación implica una ausencia de interacción social entre los grupos considerados.

Asimismo, en el siglo XIX, en el interior del casco urbano, las viviendas interiores, las corralas y casas de corredor, servían a las clases populares. Posteriormente la expansión urbana y la introducción de los transportes públicos motivarán que la distancia se convierta en el criterio diferenciador, generando la diferenciación y segregación horizontal. (García y González, 1980).

En la actualidad, en medio del predominio general de la segregación horizontal, se producen modelos divergentes como respuesta a particularidades locales del desarrollo urbano y social. Y de nuevo la segregación vertical se convierte en un paradigma alternativo cuando los atributos residenciales dentro de un mismo edificio se distribuyen de forma desigual entre los pisos, a los que se llega a través de los mecanismos del libre mercado. En el caso español, se ha mostrado una relación entre precio de la vivienda en un mismo edificio y altura a la que se localiza ésta. Así lo demuestran los diferentes estudios de mercado de Tecnocasa, una de las principales inmobiliarias del país. En el informe correspondiente al primer semestre de 2013, se indicaba que en la ciudad de Málaga el precio de las viviendas sin ascensor era 20 por ciento menor que el de aquellas otras que sí disponían de él, unos precios inferiores desde, al menos, comienzos de 2004 (Tecnocasa, 2013).

En este contexto, algunos autores han querido demostrar que la ciudad mediterránea está modelada por fuerzas diferentes a las que afectan a las ciudades del norte y oeste de Europa, lo que ha provocado entre otras 
circunstancias, la existencia de una segregación por clase social y étnica, tanto horizontal como vertical de menor magnitud que la correspondiente a la ciudad anglo-americana, y fundamentada en una débil concentración de la clase obrera con respecto a los estratos más ricos y que cuando tiene lugar es predominantemente vertical (Leontidou, 2009).

En muchas ciudades europeas, Nápoles (Dopp, 1968), Montpellier (Laquerbe, 1967), Lyon (Grafmeyer, 1991), la diferenciación vertical era un rasgo permanente de la convivencia entre las clases media y obrera en las viviendas antiguas. La clase media ocupó las plantas primera y segunda y la clase trabajadora, la planta baja y los pisos superiores, en línea con el modelo parisino y vienés (Maloutas, 2001). Un tipo más reciente de cohabitación vertical en algunas ciudades italianas, se traduce en pisos superiores aburguesados del viejo centro - especialmente cuando existen bonitas vistas y terrazas - y apartamentos más oscuros en los pisos inferiores de la clase trabajadora, inmigrantes o familias profesionalmente marginales.

En contraposición, en Atenas, la diferenciación vertical es más reciente y la experimentan nuevas promociones construidas durante los años 1960 y principios de los 70 que - a diferencia del modelo parisino - no fueron diseñados para dicho tipo de convivencia, al igual que ocurre con los barrios malagueños.

La estructura social originaria de clase media de dichas viviendas, ha evolucionado rápidamente desde mediados de la década de 1970 hacia la coexistencia de clases. Como resultado, los habitantes más pudientes de las zonas en donde se ha detectado esta diferenciación vertical, ocupan los pisos superiores y la clase trabajadora y otros trabajadores manuales, los inferiores, incluyendo la planta baja y el sótano (Maloutas, 2001; Kokkali, 2010).

Con estos precedentes, nuestro trabajo quiere comprobar si existe un modelo distinto de diferenciación y segregación vertical, ligado a la inmigración y a la exclusión residencial en la ciudad de Málaga.

Por último, no debemos dejar de apuntar que el estudio de los problemas urbanos y de la vivienda están muy vinculados con el análisis de la pobreza y la exclusión social, un término este último que comenzará a sustituir al de pobreza a partir de los año 90 del siglo XX en las políticas sociales en España, porque permite un análisis dinámico y multidimensional de dicha realidad (trabajo, ingresos, educación, salud, participación, vivienda y relaciones socio-familiares).

Estudios como el que realizamos son un instrumento para conseguir información que permita actuar en el camino de su corrección y por tanto, 
en un elemento clave en las políticas urbanas actuales que apuestan por la sostenibilidad e inclusión social, en un contexto de mayor participación ciudadana.

\section{FUENTES Y UNIDAD ESPACIAL}

Para indagar si en el municipio de Málaga se ha registrado un proceso de segregación vertical entre los inmigrantes es necesario contar con información relativa tanto a la nacionalidad de la población como a la planta del edificio en la que residen. Si bien es cierto que el origen puede ser obtenido tanto de los Censos de Población como de los Padrones Municipales de Habitantes, la correspondiente a la planta no está disponible en los primeros, pero sí puede accederse a ella en los segundos a través de procesamientos especiales. Es por ello que la totalidad de la información que emplearemos proviene del Padrón Municipal de Habitantes del municipio de Málaga.

Es un hecho que el uso del Padrón de habitantes limita el alcance temático de la información disponible y, por tanto, del conjunto de la investigación, puesto que en él tan sólo se recoge información acerca de las características estructurales de la población (edad y sexo), nacionalidad, lugar de residencia (sección o barrio) y nivel de estudios. De cualquier forma, también es preciso indicar que a efectos prácticos la fuente de información alternativa, el Censo de Población, ofrece aún menos información para 2011 —último Censo realizado en España - , puesto que al emplearse un método muestral en su realización, hay una mayoría de secciones censales para las que no puede obtenerse más información que la anteriormente reseñada.

Para dar cuenta de nuestro objetivo es necesario que la información esté referida, al menos, a dos fechas, y que sean comparables entre ambas. Desde el punto de vista temático no se plantea problema alguno, puesto que la definición de las variables empleadas (nacionalidad y planta de residencia) no ha sufrido modificaciones entre 2003 y 2013. Sin embargo, cuando se pretende comparar información referida a unidades espaciales que han variado en número o límites durante el periodo estudiado aparecen problemas potenciales, siendo el de la unidad espacial modificable (PUEM) el que más nos podría afectar. Como es sabido, el PUEM aparece cuando se calculan índices a partir de información referida a un número diferente de unidades espaciales, lo que plantea inconvenientes a la hora de comparar los resultados. Su presencia es muy frecuente cuando se utiliza la sección censal, puesto que se trata de una unidad delimitada con fines estrictamente administrativos y que experimenta cambios en su número, generalmente 
por división en las áreas periféricas de las ciudades, y por fusión en las áreas centrales (Openshaw, 1984; Garrocho y Campos-Alanís, 2013).

En este sentido, la información correspondiente al Padrón de Habitantes del municipio de Málaga está referida no sólo a las secciones censales - como lo está la totalidad de los Padrones Municipales españoles-, sino también a los barrios que conforman el municipio. Unos barrios cuyos límites fueron trazados por el Ayuntamiento de la ciudad a partir de criterios físicos, tipológicos, momento de construcción, etc., y que se han mantenido estables desde su delimitación. El empleo del barrio como unidad alternativa a la sección censal permite, por tanto, soslayar los inconvenientes causados por el PUEM, al tiempo que permite agrupar a los habitantes en unidades espaciales homogéneas desde el punto de vista de sus características formales, infraestructurales, etc. Unidad espacial tan homogénea como lo pueden ser los barrios, y, en cualquier caso, más de lo que puede aspirar a serlo una sección censal.

Dicho esto, para comprobar si se ha registrado un proceso de exclusión/ segregación residencial en altura hemos seleccionado un conjunto de 11 barrios, con características comunes. Su elección concreta obedece a una combinación de factores: por un lado, la importante presencia de extranjeros en ellos, tal y como atestiguan sus elevadas tasas de extranjería. Por otro, su condición de barrios sometidos a un proceso de progresivo deterioro físico al corresponder todos a una etapa de construcción similar, lo que se une a unas características físicas de las viviendas muy inferiores a los estándares actuales: téngase en cuenta que se levantaron como viviendas destinadas a alojar a inmigrantes interiores. Pero lo que los hace idóneos para nuestro objetivo, es el hecho de que se trata de edificaciones en altura, en todos los casos sin ascensor; así, en ellas se invierte la tendencia a que las plantas superiores sean más apetecibles, siempre que el acceso a ellas se vea facilitado por la presencia de este equipamiento. En caso contrario, como es el de estos barrios, las apetecibles son las bajas, dentro de un contexto de vivienda de bajas calidades y, por tanto, asequibles.

El periodo temporal seleccionado incluye el año 2003, primero para el que la información necesaria está disponible, y 2013, momento en el que la población extranjera en el municipio alcanzó su máximo, habiéndose reducido paulatinamente desde entonces. En 2013 estaban empadronados en los 11 barrios un total de 21260 personas, que hemos dividido en tres grupos: por un lado, los empadronados extranjeros "no laborales", considerando como tales a los provenientes de la Unión Europea de los 15, Estados Unidos, Canadá, Australia, Nueva Zelanda, Suiza, Noruega e Is- 
landia; por otro, los extranjeros laborales, grupo integrado por el resto de nacionalidades no españolas, mayoritarios; $y$, por último, los españoles.

La caracterización general de la población de los barrios ha sido realizada a partir de este total de población. Sin embargo, el objetivo de la investigación es comprobar si se ha registrado un proceso de segregación vertical, entre 2003 y 2013: es por ello que para comprobarlo hemos seleccionado únicamente aquellos empadronados cuya fecha de alta es posterior al 1 de enero de 2003, y anterior a la misma fecha de 2013; la depuración de la base de datos original nos ha llevado a eliminar aquellos registros en los que no consta la nacionalidad, la planta de residencia o ambas a la vez, lo que nos deja un total de 5701 personas: 3838 españoles, 1745 extranjeros laborales, y 118 correspondientes al resto de extranjeros. Sobre este conjunto de población, más reducido, se centra el núcleo de la investigación.

Por último, indicaremos que el tratamiento estadístico de la información ha sido realizado empleando el Cociente de Localización que, como han puesto de manifiesto algunos investigadores (Brown y Chung, 2006; Bayona y López, 2011) se presenta como un instrumento muy útil para analizar la concentración de la población extranjera. Su cálculo se ha realizado de la siguiente manera:

$$
C L=\frac{\frac{E_{o p}}{E_{O}}}{\frac{E_{P}}{E_{T}}}
$$

Donde $E_{o p}$ es el número de nuevos empadronados de origen $O$ residente en la planta $P ; E_{O}$ es el número total de nuevos empadronados de origen $O$; $E_{P}$ es el número total de nuevos empadronados residentes en la planta $P$; y $E_{T}$ es el número total de nuevos empadronados en los 11 barrios. Valores superiores a la unidad son indicativos de una sobrerrepresentación con respecto a la situación global, y los inferiores, de infrarrepresentación.

\section{Caracterización de la zona de estudio}

\section{Breve análisis histórico y caracterización física de los barrios}

Como anteriormente indicamos, son 11 los barrios seleccionados para nuestro estudio, quedando identificados en la Figura 1, y descritas sus características urbanísticas principales en la Tabla 1. 


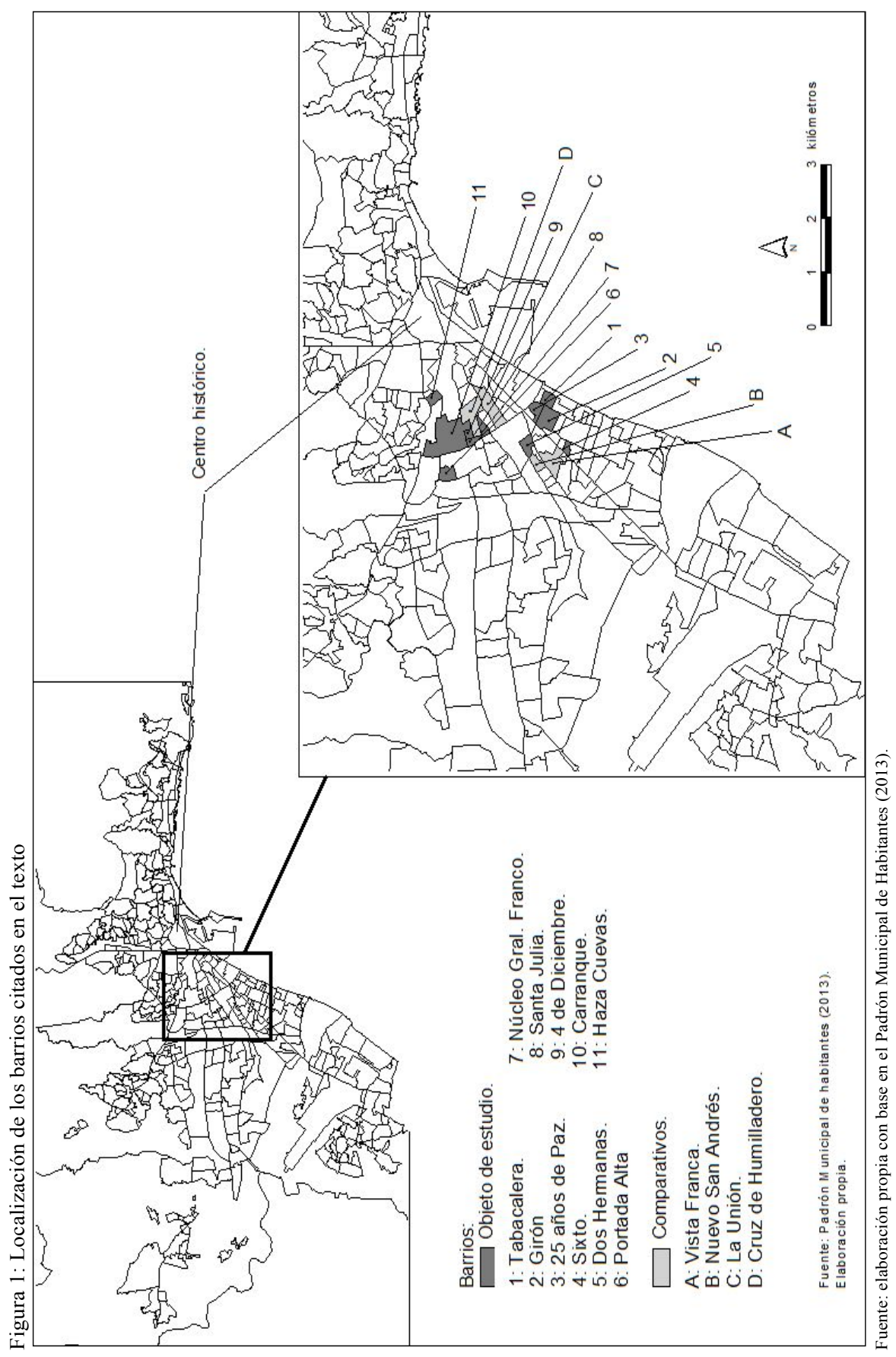


Evidencias sobre la segregación vertical en ciuddades del sur de Europa... / J.J. NATERA-RIVAS et al.

\begin{tabular}{|c|c|c|c|c|c|c|c|c|c|c|c|}
\hline 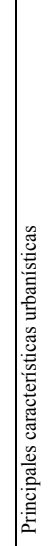 & 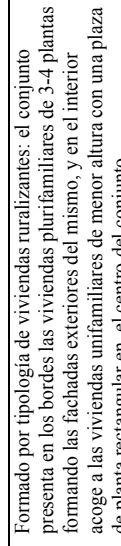 & 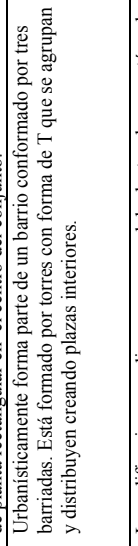 & 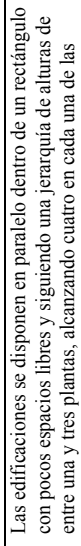 & 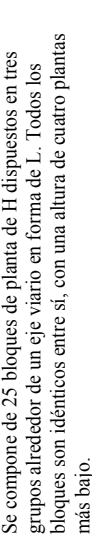 & 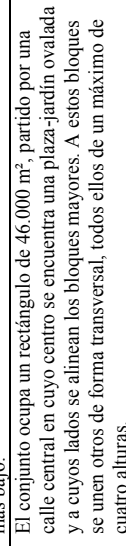 & 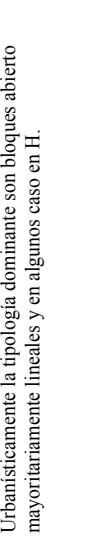 & 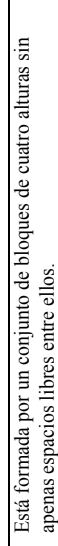 & 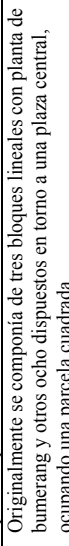 & 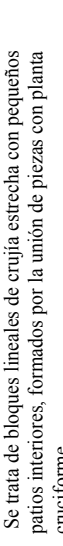 & 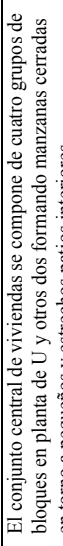 & 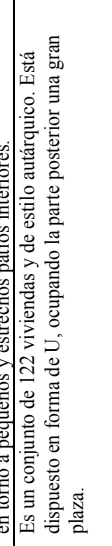 \\
\hline & 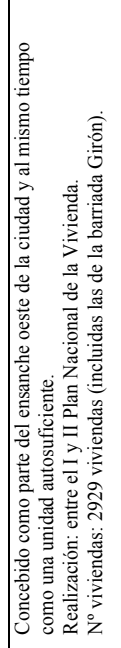 & 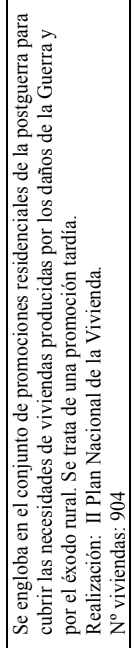 & 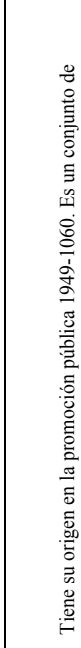 & & 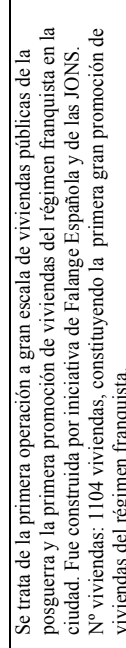 & 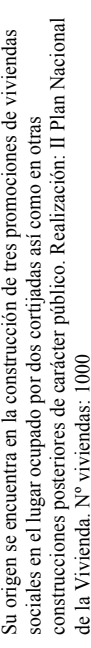 & & 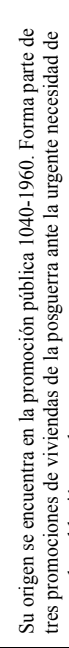 & 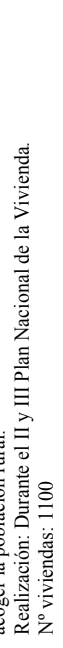 & & 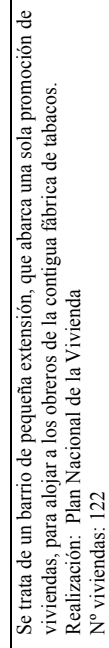 \\
\hline & 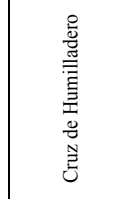 & 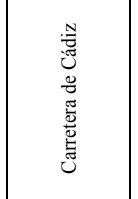 & 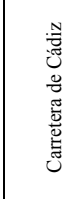 & 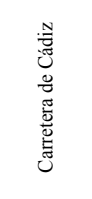 & 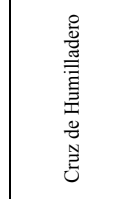 & 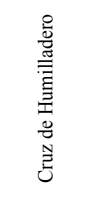 & 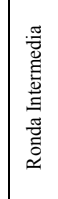 & 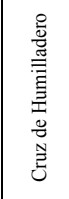 & 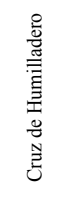 & 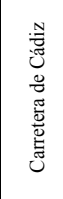 & 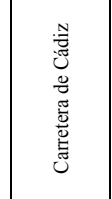 \\
\hline 일 & 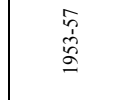 & $\bar{\Xi}$ & 总 & 号 & I & $\stackrel{\Omega}{\Omega}$ & 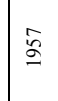 & $\stackrel{\circ}{\alpha}$ & ڤે & 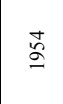 & \& \\
\hline & 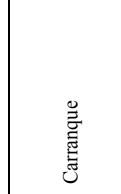 & 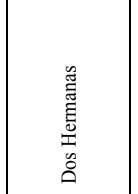 & 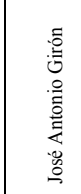 & 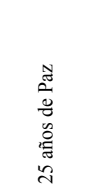 & 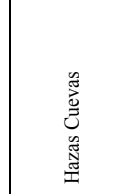 & 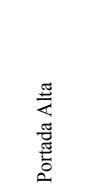 & 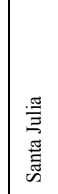 & 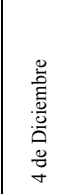 & 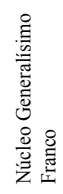 & 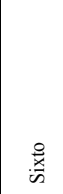 & $\stackrel{5}{\circ}$ \\
\hline
\end{tabular}


Se ubican geográficamente a lo largo de tres grandes ejes de la ciudad (Ronda Intermedia, Carretera de Cádiz y Cruz de Humilladero), y constituyeron en su momento el frente oeste de la ciudad de Málaga.

Se trata de conjuntos residenciales de la postguerra levantados en la periferia del tejido urbano con el objetivo de cubrir las necesidades de viviendas derivadas, por un lado, de los daños causados en el parque habitacional durante la Guerra Civil, un parque que ya venía arrastrando un déficit desde el período de la Segunda República y la Dictadura de Primo de Rivera; por otro lado, de la presión que sobre este parque menguado comenzaba a ejercer el éxodo rural ligado al proceso de desarrollismo español. Localizadas en el caso malagueño en su porción occidental, la más antigua de las que son objeto de nuestro estudio data de la década de los 40 (Barriada Haza Cuevas), mientras que el resto se levantó a lo largo de las décadas de los 50 y 60, en el marco de los cuatro Planes Nacionales de la Vivienda que se fueron sucediendo durante la dictadura franquista.

Responden a una tipología y diseño constructivo semejantes, acorde al espíritu ruralizante de la ciudad autárquica, y tienen en común el hecho de que están formadas por viviendas plurifamiliares en altura (aunque, en el caso de la barriada de Carranque coexisten con algunas viviendas unifamiliares de una sola planta). En las barriadas más antiguas las viviendas están insertas en bloques adosados sobre calles articuladas por una vía principal, mientras que, a partir del II Plan Nacional de la Vivienda lo están en bloques aislados en forma de $H$ o $T$, respondiendo a las primeras promociones urbanísticas destinadas al "alojamiento de masa" (Egea, 2008a; Egea, 2008 b; Arias, 2000). Sus edificaciones en altura cuentan con hasta 5/6 pisos, y, a diferencia de actuaciones posteriores, no disponen de ascensor, elemento común a todas las seleccionadas para nuestro estudio, y nunca fueron planeadas con la cohabitación social vertical en mente.

Todas ellas han venido soportando a lo largo del tiempo una degradación tanto física como social, que las convierten en espacios con bajos niveles de calidad ambiental, asociados a clases sociales de status bajo o muy bajo. En efecto, nuestras barriadas ya en los ochenta habían sido calificadas como de bajo estatus social y ciclo vital avanzado (Ocaña, 1998), una situación que no se ha revertido, como muestra el hecho de que todas, menos Haza Cuevas y Torres de la Serna, hayan sido clasificadas como barrios vulnerables por el Ministerio de Fomento (1991-2006), tras el análisis de una amplia gama de variables en las que se manifiesta la vulnerabilidad. ${ }^{2}$

\footnotetext{
${ }^{2}$ En este estudio, se entiende por vulnerabilidad urbana "aquel proceso de malestar en las ciudades producido por la combinación de múltiples dimensiones de desventaja, en el que toda esperanza de movilidad social ascendente, de superación de su condición social de exclusión o
} 
Atendiendo a la vivienda, el principal rasgo a destacar es su reducido tamaño $\left(21.9 \mathrm{~m}^{2} / \mathrm{hab}\right)$, claramente por debajo del promedio del parque residencial de la ciudad $\left(27.6 \mathrm{~m}^{2} / \mathrm{hab}\right)$, a lo que hay que añadir dos aspectos más que hacen más lamentable el estado de las viviendas: en primer lugar, la frecuencia de viviendas sin aseo es de 1.4 por ciento, en todos los casos por encima de la media municipal (1.06 por ciento); en segundo lugar, el nivel de viviendas en mal estado de conservación, en torno a 12.7 por ciento, porcentaje muy por encima del nivel medio del municipio (2.85 por ciento), una situación en la que indudablemente influye el hecho de que el grueso del parque de viviendas tiene más de 30 años.

Por otro lado, la población española ha ido progresivamente abandonándolas, y ha sido sustituida por población extranjera. Natera y Batista (2012) incluyen a nueve de los once barrios en una dinámica demográfica de "descenso de población con extranjerización" (descenso de la población total, siendo la responsable de ello la población española, mientras que la extranjera ha aumentado), al tiempo que los dos restantes (Haza Cuevas y Sixto) lo hacen en la dinámica de "aumento de población con extranjerización" (aumento de la población extranjera combinado con un descenso de la española, resultando finalmente un saldo positivo, un aumento de los volúmenes totales de población). Unas dinámicas derivadas de la aparición de viviendas vacías (por abandono de sus antiguos residentes españoles), de escasa calidad y con pocos equipamientos que, en virtud de su comparativo bajo precio (de alquiler o, en menor medida, de compra), resultan asequibles a una población extranjera, en menor medida nacional, pero en ambos casos de escasos recursos. Un fenómeno que no es exclusivo de Málaga, sino que también ha sido detectado en otras áreas metropolitanas españolas (Bayona, 2006; Alguacil, 2006; Vecina, 2013; De Esteban, 2006).

\section{Caracterización de la población estudiada}

La población residente en los 11 barrios objeto de estudio ascendía en 2013 a 21260 individuos, representando 3.72 por ciento de la población del municipio de Málaga (570 289 habitantes). Carranque es el barrio que tiene un mayor volumen de población respecto al total de la agregación (27.83 por ciento), en torno a diez por ciento de la población la reúnen cuatro barriadas (Dos Hermanas, 25 años de Paz, Portada alta y Girón), en tercer

próxima a ella, es contemplada como extremadamente difícil de alcanzar. Por el contrario, conlleva una percepción de inseguridad y miedo a la posibilidad de una movilidad social descendente, de empeoramiento de sus actuales condiciones de vida" (Ministerio de Fomento, 1991-2006). 
lugar se sitúan los barrios de Santa Julia, 4 de Diciembre y Sixto con un volumen de población cada uno entre cinco y diez por ciento, seguidos de la barriada Haza Cuevas y el Núcleo General Franco al aportar cada una en torno a cuatro por ciento de los efectivos del subconjunto; siendo el grupo Torres de la Serna el que acoge a un menor número de habitantes, tan sólo 1.06 por ciento de los veintiún mil individuos censados en 2013.

Como anteriormente indicamos, desde el punto de vista de su dinámica poblacional reciente estos barrios han experimentado en su conjunto un doble proceso: por un lado, una ligera pérdida de población en la década objeto de estudio, al pasar de los 22565 empadronados en 2003 a los 21260 actuales. Por otro, un gran incremento del número de extranjeros empadronados, pasándose de 507 en la primera fecha a 2059 en la segunda, un incremento de 1552 individuos, más de 400 por ciento. La combinación de descenso de españoles y aumento de extranjeros ha tenido como consecuencia lógica un aumento de la tasa de extranjería del conjunto que se sitúa en 9.68 por ciento, por encima de la municipal ( 8.8 por ciento). Considerando a los barrios individualmente, tan sólo tres de ellos (4 de Diciembre, Girón y Núcleo General Franco) presentan tasas por debajo de la media municipal, frente a los ocho restantes que se sitúan por encima, correspondiendo la cifra más elevada a Haza Cueva, que prácticamente duplica el valor medio municipal, coincidiendo con la primera promoción de vivienda de la posguerra, donde las condiciones de habitabilidad son más precarias, lo que la hace más asequible para este colectivo.

El carácter laboral de la inmigración extranjera que se ha asentado en estos barrios queda de manifiesto cuando consideramos, por un lado, que 54.48 por ciento de la misma tiene origen marroquí ( 25 por ciento), nigeriano ( 7.6 por ciento), ucraniano (10.3 por ciento), rumano (7.9 por ciento) y paraguayo (6.8 por ciento); por otro lado, que en contraste, aquellos otros orígenes pertenecientes a países con elevados niveles económicos, cuentan con volúmenes muy escasos. A modo de ejemplo, los nacionales de la UE15 son sólo 104, mientras que si sumamos el resto de países de la Europa Occidental, más otros países desarrollados, el total asciende a un todavía muy exiguo volumen de 118 empadronados.

La distribución individualizada de las distintas nacionalidades es un aspecto más que confirma este nuevo patrón migratorio basado en la producción (Tabla 2). De esta forma la población de origen africano aparece como el grupo mayoritario en ocho de los 11 barrios, llegando a suponer casi 90 por ciento de los extranjeros en la barriada 4 de Diciembre (prioritariamente población marroquí y nigeriana) y más de 60 por ciento en el 
N.G. Franco (con predominio de marroquíes y argelinos) y Portada Alta (marroquíes y nigerianos). Frente a ello, los extranjeros de procedencia europea aunque también se imponen en cuatro zonas, su peso es menos significativo al representar entre 35 y 50 por ciento de la población inmigrante de las barriadas 25 años de Paz, Sixto, Carranque y Girón, donde las nacionalidades más representativas son la ucraniana y la rumana. Por último, dentro de la escasa presencia de la inmigración americana, ésta se impone en el barrio de Haza Cuevas (paraguayos, bolivianos y argentinos son los fundamentales) y en el Grupo Torre de la Serna, donde es la nacionalidad armenia la más representativa.

Tabla 2: Distribución de los extranjeros según su origen (valores porcentuales)

\begin{tabular}{lrrrrrr}
\hline & Europa & África & América & $\begin{array}{r}\text { Asia y } \\
\text { Oceanía }\end{array}$ & $\begin{array}{r}\text { Apátrida y } \\
\text { desconocido }\end{array}$ & $\begin{array}{r}\text { Total } \\
\text { extranjeros }\end{array}$ \\
\hline Málaga & 3.12 & 2.49 & 2.53 & 0.63 & 0.03 & 8.8 \\
Agregación & 3.12 & 3.82 & 2.26 & 0.45 & 0.03 & 9.68 \\
25 paz & 5.98 & 4.66 & 3.11 & 0.61 & & 14.35 \\
4 de diciembre & 0.19 & 4.45 & 0.32 & & & 4.97 \\
B. Girón & 2.8 & 1.36 & 1.6 & 0.08 & & 5.84 \\
Carranque & 3.19 & 2.48 & 2.35 & 0.68 & & 8.71 \\
Dos Hermanas & 1.66 & 3.88 & 2.06 & 0.5 & & 8.1 \\
Haza de Cuevas & 3.83 & 6.19 & 6.29 & 0.1 & & 16.42 \\
N.G.Franco & 1.86 & 4.3 & 0.23 & & 0.12 & 6.51 \\
P. Alta & 2.77 & 7.1 & 1.73 & & & 11.6 \\
S. Julia & 4.91 & 5.64 & 3.5 & 0.43 & & 14.48 \\
Sixto & 3.89 & 2.4 & 1.49 & 1.32 & & 9.11 \\
T.Serna & 1.77 & 0.44 & 4.42 & 2.65 & & 9.29 \\
\hline
\end{tabular}

Fuente: elaboración propia con base en el Padrón municipal de habitantes (2013).

El análisis de algunos rasgos estructurales de los inmigrantes laborales (Tabla 3) y su comparación con la población total de la agregación y del conjunto de la ciudad, nos permite verificar algunas de las características que marcan los procesos migratorios en la actualidad. En relación a la estructura por sexo, entre los inmigrantes laborales la relación de masculinidad se declina hacia la población masculina ( 51.74 por ciento), al contrario de lo que se aprecia en el total de la población de estos barrios y en la capital, si bien hay que tener presente el peso que está adquiriendo la población femenina, especialmente en los colectivos procedentes de Latinoamérica y 
Países del Este de Europa en consonancia con lo puesto de manifiesto en estudios realizados a nivel andaluz (Larrubia, 2014). Frente a una estructura etaria envejecida de la población de estos barrios, la estructura por edad de los inmigrantes laborales refrenda el carácter económico de estas nuevas corrientes, ya que la población en edad de trabajar (entre 15 y 64 años) representa 82.72 frente a 68 por ciento de la población los barrios. Por último, los bajos niveles de instrucción es un elemento más que significan a estos barrios, una situación que es extrapolable a la totalidad de los 11 barrios, pero que se agrava en el colectivo de inmigrantes, de forma que casi 44 por ciento de estos inmigrantes no tienen estudios básicos, frente a 40 por ciento de la agregación. Igualmente la población inmigrante que posee estudios medios es la mitad (5.48 por ciento) de la existente en el conjunto de los barrios.

Tabla 3: Características estructurales de la población extranjera laboral (2003-2013)

\begin{tabular}{lrr}
\hline & Población & $\%$ \\
\hline Estructura por sexo & & \\
Mujer & 846 & 48.26 \\
Varón & 907 & 51.74 \\
Estructura por edad & & \\
$<15$ & 271 & 15.46 \\
$15-64$ & 1450 & 82.72 \\
$>64$ & 32 & 1.83 \\
Nivel de instrucción & 151 & 8.61 \\
Analfabetos $>10$ & 72 & 4.11 \\
analfabetos $<10$ & 542 & 30.92 \\
Inferior estudios básicos & 400 & 22.82 \\
Estudios básicos & 96 & 5.48 \\
Estudios medios & 65 & 3.71 \\
Estudios superiores & 427 & 24.36 \\
Desconocido & 1753 & 100.00 \\
Total población & & \\
\hline
\end{tabular}

Fuente: elaboración propia con base en el Padrón Municipal de habitantes.

\section{Pautas de segregación vertical de la población INMigrante en Málaga}

En el apartado anterior se han analizado las características generales de la población residente en la agregación de los 11 barrios seleccionados, del tejido urbano en el que reside, y de la dinámica poblacional que le ha afectado en la última década. 
Es este el contexto en el que debemos plantearnos si durante el proceso de incremento de la población foránea en los barrios objeto de estudio, se ha registrado un proceso de segregación vertical o, si por el contrario, el acceso a las plantas más deseables — en este caso, las de menor alturase ha producido en las mismas proporciones que el correspondiente a los españoles. Recordemos que para dilucidar esta cuestión nos centraremos en la población que se ha incorporado a los 11 barrios en el periodo 20032013, un total de 5701 personas para los que tenemos información sobre la planta en la que residen: 3838 españoles y 1863 extranjeros, de los cuales 118 provienen de países desarrollados, y el resto, 1745 , de otros orígenes, grupo que hemos considerado como inmigrantes laborales.

En la Tabla 4 y en la Figura 2 se muestra la distribución de los tres grupos en números absolutos y en porcentajes, y en ellos puede observarse cómo el acceso a las plantas ha sido diferente según el grupo al que hagamos referencia. Algo menos de un tercio de los nuevos empadronados españoles accedieron a una vivienda en la planta baja, porcentaje que sube ligeramente por encima de 50 por ciento si a ellos se añaden los residentes en la primera de las plantas del edificio, y que se eleva a las tres cuartas partes si añadimos a su vez a los nuevos empadronados en la segunda planta; en otras palabras, son la planta baja y las dos primeras sobre rasante las que han acogido a tres de cuatro españoles empadronados en los barrios objeto de estudio, observándose un descenso muy acusado a partir de esta última altura. Es también importante señalar que existe un descenso sistemático de los porcentajes conforme subimos en altura.

Tabla 4: Distribución de los empadronados según origen y planta, números absolutos y porcentajes

\begin{tabular}{lrrrrrrr}
\hline & Total & Españoles & $\begin{array}{r}\text { Extranjeros } \\
\text { laborales }\end{array}$ & $\begin{array}{r}\text { Resto } \\
\text { extranjeros }\end{array}$ & $\begin{array}{r}\% \\
\text { españoles }\end{array}$ & $\begin{array}{r}\text { \% extra. } \\
\text { Laborales }\end{array}$ & $\begin{array}{r}\% \text { resto } \\
\text { extranjeros }\end{array}$ \\
\hline PBJ & 1542 & 1169 & 339 & 34 & 30.46 & 19.43 & 28.81 \\
P01 & 1314 & 833 & 447 & 34 & 21.70 & 25.62 & 28.81 \\
P02 & 1208 & 798 & 387 & 23 & 20.79 & 22.18 & 19.49 \\
P03 & 1007 & 609 & 378 & 20 & 15.87 & 21.66 & 16.95 \\
P04 & 451 & 294 & 153 & 4 & 7.66 & 8.77 & 3.39 \\
P05 & 84 & 63 & 21 & 0 & 1.64 & 1.20 & \\
P06 & 52 & 36 & 13 & 3 & 0.94 & 0.74 & 2.54 \\
P07 & 15 & 11 & 4 & 0 & 0.29 & 0.23 & \\
P08 & 11 & 11 & 0 & 0 & 0.29 & & \\
P09 & 8 & 8 & 0 & 0 & 0.21 & & \\
P10 & 9 & 6 & 3 & 0 & 0.16 & 0.17 & \\
Total & 5701 & 3838 & 1745 & 118 & 100.00 & 100.00 & 100.00 \\
\hline
\end{tabular}

Fuente: elaboración propia con base en el Padrón Municipal de habitantes. 


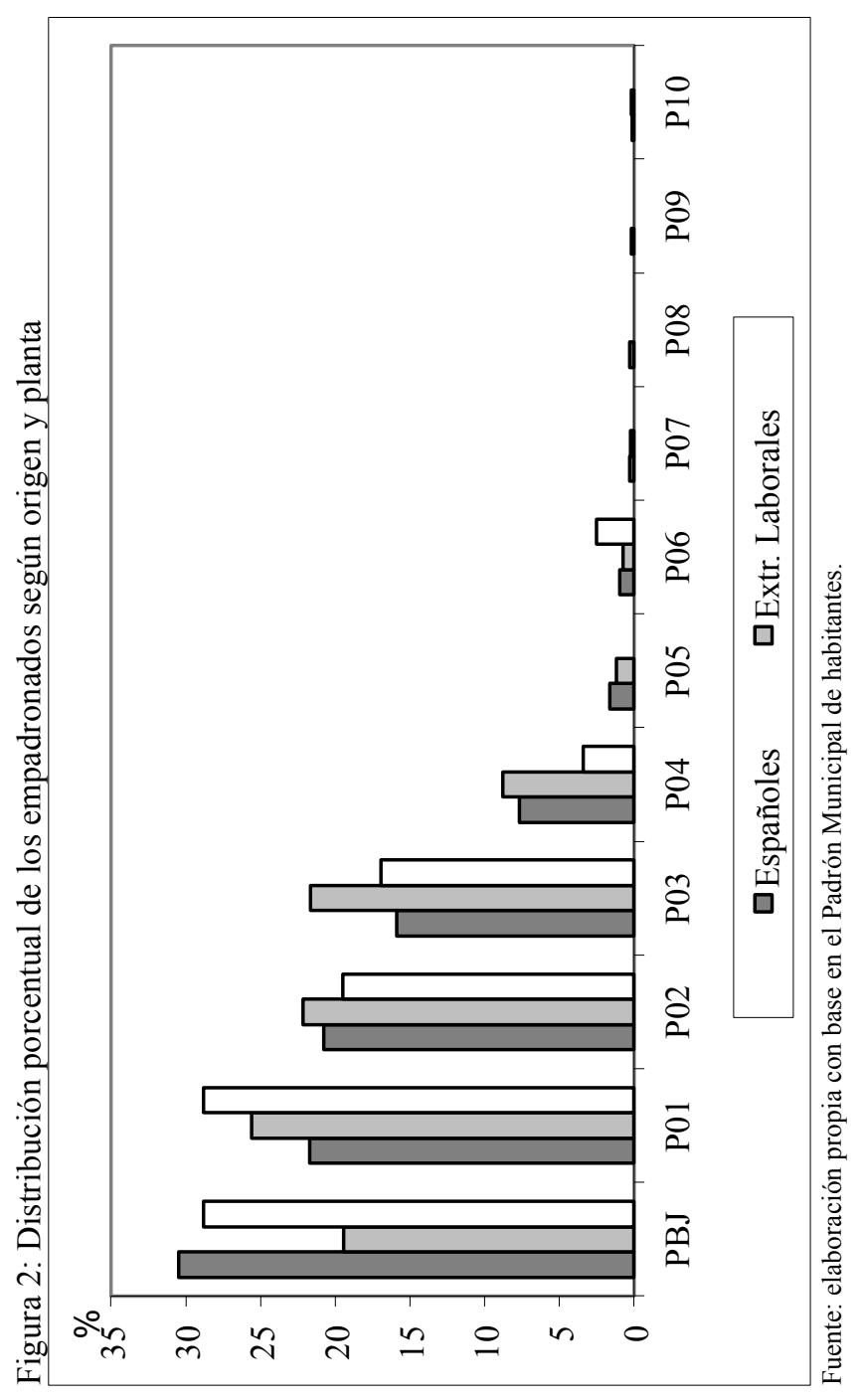


Esta distribución contrasta notablemente con la correspondiente a los extranjeros laborales: en su caso tan sólo 19.43 por ciento pudo acceder a las viviendas de la planta baja, siendo más numerosos los que fueron a residir en las plantas primera a tercera. Ciertamente en este contingente también puede observarse el descenso de los porcentajes conforme incrementamos la altura, pero este descenso comienza a partir de la primera planta (no de la planta baja, como en el caso de los españoles), y los porcentajes son más elevados con respecto a ellos.

Por último, la distribución correspondiente al resto de los extranjeros es muy similar a la de los españoles, con el grueso de la población en las plantas inferiores, y un sistemático descenso de la misma conforme aumentamos la altura.

Una visión complementaria, y tal vez más ajustada, nos la aporta el empleo del Cociente de Localización, puesto que sus resultados muestran la sobrerrepresentación o la infrarrepresentación de cada grupo en cada planta con respecto al peso que tienen en el total de nuevos empadronados. La información se muestra en la Tabla 5.

Tabla 5: Distribución de los empadronados según origen y planta, números absolutos y cocientes de localización

\begin{tabular}{lrrrrr}
\hline & Total & Españoles & $\begin{array}{r}\text { Extranjeros } \\
\text { laborales }\end{array}$ & CL españoles & $\begin{array}{r}\text { CL extra. } \\
\text { Laborales }\end{array}$ \\
\hline PBJ & 1542 & 1169 & 339 & 1.13 & 0.72 \\
P01 & 1314 & 833 & 447 & 0.94 & 1.11 \\
P02 & 1208 & 798 & 387 & 0.98 & 1.05 \\
P03 & 1007 & 609 & 378 & 0.90 & 1.23 \\
P04 & 451 & 294 & 153 & 0.97 & 1.11 \\
P05 & 84 & 63 & 21 & 1.11 & 0.82 \\
P06 & 52 & 36 & 13 & 1.03 & 0.82 \\
P07 & 15 & 11 & 4 & 1.09 & 0.87 \\
P08 & 11 & 11 & 0 & 1.49 & \\
P09 & 8 & 8 & 0 & 1.49 & \\
P10 & 9 & 6 & 3 & 0.99 & 1.09 \\
Total & 5701 & 3838 & 1745 & 1 & 1 \\
\hline
\end{tabular}

Fuente: elaboración propia con base en el Padrón Municipal de habitantes.

En ella puede observarse cómo el grupo de los españoles presenta un sobrepeso en la planta baja, y una sistemática infrarrepresentación en el resto, hasta la cuarta altura. Por su parte, los valores de los extranjeros 
laborales son diametralmente opuestos, infrarrepresentación en la planta baja, y sobrepeso sistemático en el resto, también hasta la cuarta planta.

Estas diferencias se aprecian con más claridad en la Figura 3, en el que hemos resaltado el valor 1, indicativo de que el peso de cada grupo en una planta concreta es el mismo que el que tienen en el total de la población. Puede observarse con claridad cómo los valores de los españoles están por encima de uno en la planta baja, y por debajo en el resto, situación que es justamente la contraria a la de los inmigrantes extranjeros laborales.

Venimos haciendo la salvedad de que estas dinámicas se aprecian claramente hasta la cuarta planta, oscureciéndose a partir de ella. Este hecho creemos que se debe a los pequeños contingentes de población que residen en las viviendas situadas en las plantas superiores: tal y como queda reflejado en la Tabla 5, las plantas cinco a diez agrupan a tan sólo 179 individuos, 3.13 por ciento del total de los nuevos empadronados, lo que probablemente hace que la casuística individual aflore, influyendo decisivamente en los valores del cociente de localización. Por tanto, las dinámicas contrapuestas en el acceso a las plantas más deseables por parte de españoles y extranjeros laborales pueden rastrearse con claridad allí donde los volúmenes de población son significativos (la planta baja y las primeras cuatro sobre el rasante agrupan a 97 por ciento de los nuevos empadronados), al tiempo que se diluye a partir de este nivel, donde reside una fracción muy minoritaria de la población.

Las evidencias de la existencia de segregación vertical pueden observarse no sólo en los barrios tomados como un conjunto, sino también en los barrios tomados de forma individual. Ejemplo de ello es el reparto en tres barrios concretos: Carranque, el de mayor población; Haza Cuevas, el más antiguo, y Tabacalera, uno de los más pequeños. El empleo de los cocientes de localización muestra con claridad las tendencias registradas en la agregación (Tabla 6). Sobrepeso de los españoles en las plantas bajas, y descenso sistemático del cociente conforme subimos en altura (la excepción, Tabacalera, donde el cociente de la planta uno iguala al de la baja). En el caso de los inmigrantes laborales, la situación es la contraria: infrarrepresentación en las plantas bajas y sobrepeso en el resto de plantas, con tendencia al aumento del valor con la altura. En el caso de Carranque se aprecia incluso cómo la tendencia se diluye a partir de la quinta planta, y hasta la octava, igual que ocurre en el caso de la agregación. Alturas en las que fueron empadronados tan sólo 58 personas entre los tres grupos, 3.86 por ciento del total. 
Evidencias sobre la segregación vertical en ciuddades del sur de Europa... / J.J. NATERA-RIVAS et al.

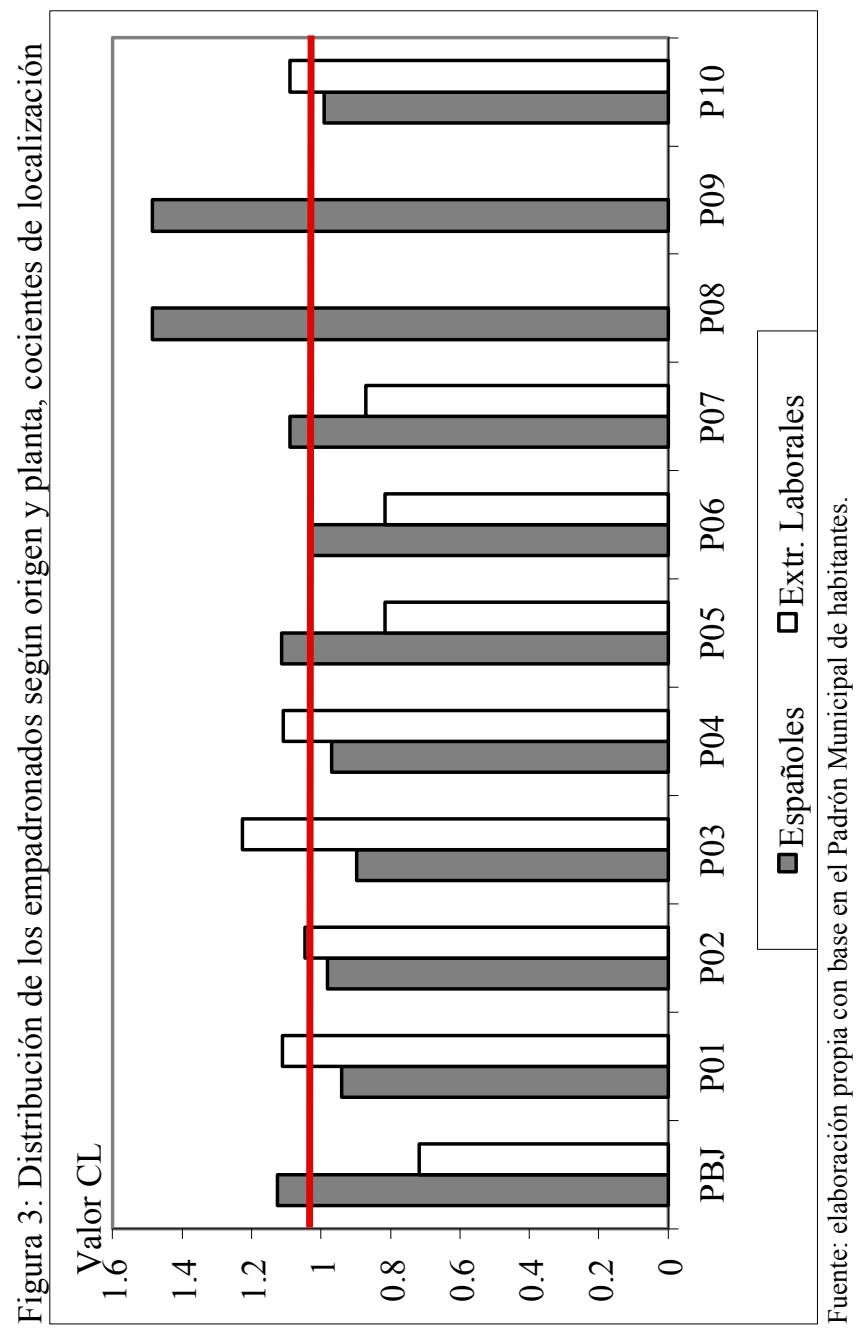


Tabla 6: Distribución de los nuevos empadronados según origen y planta, y cociente de localización (Barrios Haza Cuevas y Tabacalera)

\begin{tabular}{|c|c|c|c|c|c|c|}
\hline \multirow[b]{2}{*}{ Planta } & \multicolumn{2}{|c|}{ Carranque } & \multicolumn{2}{|c|}{ Haza Cuevas } & \multicolumn{2}{|c|}{ Tabacalera } \\
\hline & Españoles & $\begin{array}{r}\text { Extranjeros } \\
\text { laborales } \\
\end{array}$ & Españoles & $\begin{array}{r}\text { Extranjeros } \\
\text { laborales } \\
\end{array}$ & Españoles & $\begin{array}{r}\text { Extranjeros } \\
\text { laborales }\end{array}$ \\
\hline PBJ & 1.17 & 0.6 & 1.26 & 0.63 & 1.08 & 0.88 \\
\hline $\mathrm{P} 01$ & 0.87 & 1.28 & 0.95 & 1.11 & 1.08 & 1.08 \\
\hline $\mathrm{P} 02$ & 0.94 & 1.16 & 0.91 & 1.12 & 0.71 & 1.15 \\
\hline P03 & 0.83 & 1.42 & 0.88 & 1.15 & & \\
\hline P04 & 0.98 & 1.09 & & & & \\
\hline P05 & 1.02 & 1.02 & & & & \\
\hline P06 & 1.3 & 0.35 & & & & \\
\hline P07 & 1.2 & 0.59 & & & & \\
\hline $\mathrm{P} 08$ & 1.44 & 0 & & & & \\
\hline
\end{tabular}

Fuente: elaboración propia con base en el Padrón Municipal de habitantes.

Por otro lado, también podemos plantearnos si esta situación afecta tan sólo a los extranjeros laborales tomados como un conjunto, o si bien podría apreciarse alguna diferencia entre las distintas nacionalidades que los conforman. Para ello hemos tomado las cinco con mayor presencia en nuestros barrios: ucranianos, paraguayos, marroquíes, nigerianos y rumanos. En la Tabla 7 mostramos los cocientes de localización por planta correspondientes a cada una de ellas, más los correspondientes a los españoles, como elemento de comparación. En ella se aprecia claramente cómo una vez más, y con la única excepción de los paraguayos, la totalidad de los inmigrantes laborales presentan una clara infrarrepresentación en la planta baja, y una sobrerrepresentación en las superiores. Esto es, a nivel de nacionalidad, se repite la pauta del conjunto de los extranjeros laborales. Como acabamos de indicar, la excepción son los paraguayos, única nacionalidad que está sobrerrepresentada, si bien ligeramente, en la planta baja. Este hecho está en consonancia con otros hallazgos, indicativos de una situación residencial más favorable al conjunto de los latinoamericanos: presentan niveles de diferenciación residencial más bajos y niveles de exclusión residencial menores que el resto de los inmigrantes laborales (Natera, 2015).

A la vista de la información anterior, pareciera que efectivamente se ha registrado un proceso de segregación vertical en los barrios objeto de estudio. No obstante, creemos necesario comparar los resultados con los 
correspondientes a barrios localizados en las mismas áreas que los estudiados, compuestos también por edificaciones en altura pero que, a diferencia de los anteriores, sí cuentan con ascensor. Los barrios seleccionados para la comparación son Nuevo San Andrés, Cruz del Humilladero, Vistafranca y La Unión. Se trata también en todos los casos de barrios definidos como vulnerables, sus momentos de construcción son una o dos décadas posteriores, y son claros exponentes de promociones destinadas al alojamiento en masa. En ellos también la presencia de extranjeros es elevada, la tasa de extranjería asciende a 35.2 por ciento, y son también mayoría los foráneos laborales: de los 2193 extranjeros empadronados en 2013, 2080 pertenecen a este grupo.

Tabla 7: Cocientes de localización de los empadronados de las principales nacionalidades, por planta

\begin{tabular}{lrrrrrr}
\hline Planta & Españoles & Marroquíes & Ucranianos & Rumanos & Nigerianos & Paraguayos \\
\hline PBJ & 1.13 & 0.57 & 0.55 & 0.53 & 0.86 & 1.02 \\
P01 & 0.94 & 1.29 & 0.95 & 1.37 & 1.17 & 1.08 \\
P02 & 0.98 & 1.22 & 1.27 & 1.05 & 0.99 & 1.10 \\
P03 & 0.90 & 1.02 & 1.65 & 1.14 & 1.44 & 1.27 \\
P04 & 0.97 & 1.30 & 0.90 & 1.36 & 0.47 & 0.11 \\
P05 & 1.11 & & & 0.49 & & 0.57 \\
P06 & 1.03 & 0.75 & & & & \\
P07 & 1.09 & & & & & \\
P08 & 1.49 & & & & & \\
P09 & 1.49 & & & & & \\
P10 & 0.99 & & & & & \\
\hline
\end{tabular}

Fuente: elaboración propia con base en el Padrón Municipal de habitantes.

En la Figura 4 puede comprobarse cómo en estos barrios la tendencia a la distribución de la población según planta no es tan clara como la anterior, pudiéndose detectar justamente la contraria: una sobrerepresentación de inmigrantes laborales en las plantas más bajas, y un mayor peso de los españoles en las más elevadas.

El desglose por nacionalidad también muestra cómo, con la única excepción de los nigerianos, los inmigrantes laborales están sobrerrepresentados en la planta baja. Además, puede detectarse, si bien de manera difusa, una tendencia a la infrarrepresentación en las plantas más elevadas, las más apetecibles y, por lo tanto, más caras, debido a la presencia de ascensor en estas edificaciones en altura (Tabla 8). 


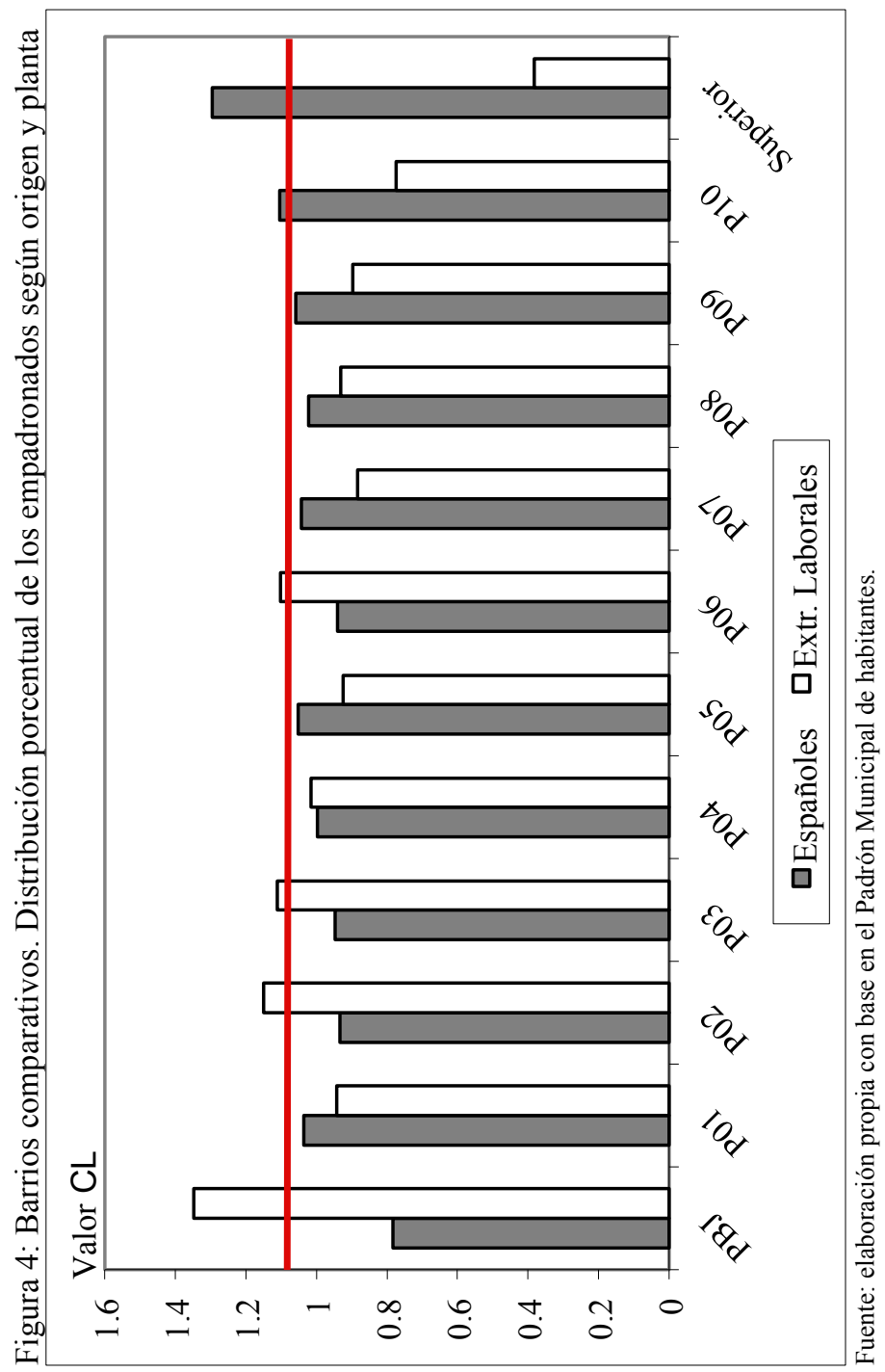


Tabla 8: Barrios comparativos. Cocientes de localización de los empadronados de las principales nacionalidades, por planta

\begin{tabular}{lrrrrrr}
\hline Planta & Españoles & Marroquíes & Ucranianos & Rumanos & Nigerianos & Paraguayos \\
\hline PBJ & 0.78 & 3.24 & 1.28 & 1.72 & 0.61 & 1.84 \\
P01 & 1.04 & 1.51 & 1.05 & 0.79 & 0.90 & 0.66 \\
P02 & 0.93 & 1.36 & 1.32 & 1.48 & 0.89 & 1.17 \\
P03 & 0.95 & 1.20 & 0.81 & 0.78 & 1.13 & 1.24 \\
P04 & 1.00 & 0.87 & 0.76 & 0.89 & 0.95 & 0.97 \\
P05 & 1.05 & 1.52 & 0.95 & 0.43 & 0.67 & 1.94 \\
P06 & 0.94 & 0.79 & 2.08 & 1.20 & 0.74 & 1.12 \\
P07 & 1.04 & 0.47 & 0.27 & 1.79 & 0.93 & 0.33 \\
P08 & 1.02 & 0.14 & 1.01 & 0.86 & 1.98 & 0.76 \\
P09 & 1.06 & & 0.44 & 0.96 & 1.74 & 0.67 \\
P10 & 1.10 & & 1.59 & 0.30 & 0.75 & 0.17 \\
\hline
\end{tabular}

Fuente: elaboración propia con base en el Padrón Municipal de habitantes.

\section{Conclusiones}

El fenómeno migratorio que se ha desarrollado en estás últimas décadas en las ciudades españolas ha supuesto cambios importantes. Hemos visto como el proceso ha ido acompañado de transformaciones y diversificación socioeconómica y cultural, especialmente en aquellos barrios y ciudades donde se asienta esta corriente de forma mayoritaria, como es el caso de la ciudad de Málaga. El rápido crecimiento y la heterogeneidad de estos flujos migratorios, ha incrementado el interés por su análisis desde diversas perspectivas, entre las que destaca la distribución espacial de este colectivo atendiendo no sólo a sus pautas de distribución territorial, sino también a los procesos de segregación socioespacial.

En este sentido, hay que apuntar que, si bien, el análisis de la segregación residencial tiene una larga trayectoria académica a partir, especialmente, de los estudios desarrollados por la Escuela de Chicago en los inicios del siglo XX, lo cierto es que en estos estudios ha primado el análisis de la segregación de carácter horizontal como forma de manifestarse las desigualdades espaciales de los diferentes grupos que habitan en la ciudad, generándose, así, la división social del espacio urbano. Si bien, los estudios recientes sobre la inserción residencial de la población extranjera en las ciudades españolas y sudeuropeas ofrecen unos valores de segregación reducidos o relativamente moderados, lo cual parece indicar que estos valores de segregación no informan correctamente de la exclusión residencial que sufren los inmigrantes (Bayona y López, 2011). Ante ello y, como ya 
se ha detectado en muchas ciudades europeas, se está imponiendo la segregación de carácter vertical motivada por el aumento de la precariedad de la situación residencial de la población extranjera, de forma que son las características de la vivienda donde residen el principal factor que traduce la nueva realidad.

Es por ello que a lo largo de estas páginas hemos intentado establecer posibles situaciones de segregación vertical en 11 barrios malagueños catalogados por el Ministerio de Fomento como vulnerables al concurrir en ellos una serie de parámetros sociodemográficos, económicos y residenciales que los sitúan en esta situación.

Son barrios sometidos a un proceso de progresivo deterioro físico (su construcción se realiza entre 1940 y 1960), y sus viviendas tienen unas características físicas muy inferiores a los estándares actuales: edificaciones en altura, pero sin ascensor, pequeño tamaño, escasa calidad y pocos equipamientos que en virtud de su comparativo bajo precio (de alquiler o, en menor medida, de compra), resultan asequibles a una población extranjera, en menor medida nacional, pero en ambos casos de escasos recursos.

La dinámica poblacional de estos barrios (pérdida de población pero aumento de la población foránea, lo que incide en una elevadas tasas de inmigración) es un proceso que también identifica a los barrios catalogados como vulnerables y/o desfavorecidos. Asimismo presenta una estructura por edad incluida en el intervalo de población activa, en consonancia con el carácter económico de las migraciones y unos bajos niveles de formación y un aumento paulatino de la población femenina.

El trabajo presentado pretende abrir nuevas líneas de investigación en un campo poco explorado como es la segregación residencial vertical, siendo los resultados más destacables los siguientes:

La segregación residencial de carácter vertical es un hecho comprobado en la ciudad de Málaga, favorecido por la relación directa que se da en España entre el precio de la vivienda en un mismo edificio y altura a la que se localiza ésta, siendo, de esta forma, las plantas superiores más apetecibles que las bajas dentro de un contexto de viviendas de bajas calidades.

El acceso a las plantas de las viviendas de los tres grupos identificados (extranjeros "no laborales", extranjeros "laborales", españoles) no ha resultado homogéneo. Tanto la población española como los extranjeros no laborales se decantan por la planta baja y las dos primeras sobre rasante, (en más de 75 por ciento). Situación que contrasta con el colectivo de extranjeros laborales, donde apenas 20 por ciento han podido acceder a esas plantas inferiores. 
Una visión complementaria nos la ha aportado el empleo del Cociente de Localización, que nos informa de que los españoles presentan un sobrepeso en la planta baja, y una sistemática infrarrepresentación en el resto, hasta la cuarta altura. Por su parte, los valores de los extranjeros laborales son diametralmente opuestos, infrarrepresentación en la planta baja, y sobrepeso sistemático en el resto, también hasta la cuarta planta. A nivel de nacionalidades vemos como se repite el patrón comentado, a excepción de los paraguayos, que atendiendo a estudios previos cuentan al igual que la mayor parte de los latinoamericanos de una diferenciación y segregación residencial menos clara.

Para verificar que esta segregación vertical sólo es extrapolable a situaciones de carencias habitacionales de las viviendas se ha realizado un análisis de la distribución por plantas de los inmigrantes laborales en barrios de creación posterior (mayor altura de sus viviendas, con ascensor y elevadas tasas de extranjería), habiéndose podido constatar en ellos la situación contraria a la que venimos observando, esto es, una sobrerrepresentación de inmigrantes laborales en las plantas más bajas, y por contra un mayor peso de los españoles en las más elevadas.

Como conclusión final se puede apuntar que al ser la segregación residencial vertical un tema relativamente nuevo, será interesante prestar especial atención a la evolución a corto y medio plazo del proceso analizado a lo largo del presente trabajo, desde el momento en que los procesos de segregación espacial van ligados a los de vulnerabilidad, debido a que los colectivos vulnerables se ven abocados a ubicarse en aquellos lugares donde la vivienda es más asequible, pero también peor dotada, en barrios con deficiente calidad ambiental, más distanciados del trabajo y de los equipamientos, y frecuentemente con problemas de aislamiento físico y de accesibilidad.

En este sentido, un incremento de población laboral inmigrante de bajos recursos en este conjunto de barrios, ya de por sí con unas connotaciones de bajas calidades constructivas, puede dar lugar a la percepción por parte del resto de habitantes de Málaga de que están siendo el reducto de la población más necesitada de la ciudad; a las carencias infraestructurales, efectivamente presentes, pueden unirse procesos incipientes de estigmatización de sus habitantes. Una situación que debe tenerse en cuenta desde las instituciones (locales y autonómicas) con competencia tanto en materia de ordenación territorial urbana como en lucha contra la exclusión social. 


\section{REFERENCIAS BIBLIOGRÁFICAS}

Alguacil Gómez, J., 2006, "Barrios desfavorecidos: diagnóstico de la situación española", en Vidal Fenández, F (dir), V informe FUHEM de políticas sociales: la exclusión social y el estado del Bienestar en España, Madrid, FUHEM, págs. 155-168.

Anselin, L., 1995, "Local Indicator of spatial Association-LISA", en Geographical analysis, núm. 27, págs. 93-1151

Arbaci, S. y Malheiros, J., 2010, "De-Segregation, peripheralisation and the social exclusion of inmigrants: Southern European Cities in the 1990s", in Journal of Ethnic and Migration Studies, núm. 36:2, págs. 227-255.

Arias Goytre, F., 2000, La desigualdad urbana en España. Ministerio de Fomento. Centro de publicaciones. Madrid.

Ayuntamiento de Málaga, 2010, Plan general de ordenación urbanística de Málaga. Gerencia Municipal de Urbanismo, obra e infraestructura. Memoria de información. Título III, págs. 134-184.

Bayona i Carrasco, J. y López Gay, A, 2011, “Concentración, segregación y movilidad residencial de los extranjeros en Barcelona" en Documents d'Análisis Geográfica, vol. 57/3, págs 381-412.

Bayona i Carrasco, J., 2006, "La segregación residencial de la población extranjera en Barcelona: ¿una segregación fragmentada?", en Scripta Nova. Revista electrónica de Geografía y Ciencias Sociales, vol. 9, núm. 235. Universidad de Barcelona. Disponible en http://www.ub.edu/geocrit/sn/sn-235.htm

Brown, L y Chung, S.Y., 2006, "Spatial segregation, segregation indices and the geographical perspectives", in Population, Space and Place, 12, págs.125-143.

De Esteban A. y Perrelló, S., 2006, "Inmigración y nuevos guetos urbanos", en Sistema: Revista de Ciencias Sociales, núm. 190-191, págs.167-178.

Dopp, W., 1968, “Die Altstadt Napoli: Entwicklung und Structur”, en Marburger Geographishe. Schriften, núm. 37.

Egea Jiménez, C. et al., 2008a, Vulnerabilidad del tejido social de los barrios desfavorecidos de Andalucía: Análisis y potencialidades. Centro de Estudios Andaluces. Junta de Andalucía, 380 págs.

Egea Jiménez, C., 2008b, "Zonas desfavorecidas-potencialmente vulnerables y respuesta vecinal. Estudio de Torreblanca, Sevilla (España)", en ALAP (edt.), Pobreza y vulnerabilidad: enfoques y perspectivas, Rio de Janeiro, ALAP, FNUAP.

Escolano Utrilla, S., 2007, "La medida de la segregación residencial urbana: análisis multiescala mediante índices de lagunaridad", en Geofocus. Revista Internacional de Ciencia y Tecnología de la Información Geográfica, núm, 7, págs. 216-234.

Fernández Salinas, V., 2001, "Las tendencias demográficas recientes de la población andaluza”, en Revista Eria, núm. 54-55, págs. 77-94 
Fullaondo, A., 2007, "La segregación residencial. Valoraciones e indicadores", aportación realizada al Seminario: Experiencias para el alojamiento y el habitar de la población migrada en Andalucía. Sevilla 5-7 de marzo 2007.

García Bellido, J. y González Tamrit, L., 1980, Para comprender la ciudad: claves sobre los procesos de producción del espacio. Nuestra Cultura. Madrid.

Garrocho, C., y Campos-Alanís, J., 2013, "Réquiem por los indicadores no espaciales de segregación residencial”, en Papeles de Población, núm. 77, págs. 269-300.

Grafmeyer, Y., 1991, Habiter Lyon. Millieux et quartiers du centre-ville. CNRSPresses Universitaires de Lyon, Paris-Lyon.

Jiménez Díaz, J.C., 1982, “El urbanismo de la autarquía en Málaga (1937-1959): el caso de la barriada de Carranque”, en Baetica, núm. 5, págs. 59-100.

Jiménez Díaz, J.C y Rubio Díaz, A., 1980, "Notas sobre el urbanismo de la Autarquía: algunas realizaciones en Málaga (1937-1959)”, en Baetica, núm 3, págs. 59-80.

Kokkali, I., 2010, Spatial proximity and social distance: Albanian migrant's invisible exclusions. Evidence from Greece, Paper prepared for presentation ate the World Bank International Conference on Poverty and Social Inclusion in the Western Balkans. Brussels, Belgium, December 2010.

Laquerbe, J. 1967, “La Population des quartiers historiques à Montpellier”, en Economie Meridionale, vol. 60, núm. 4, pp. 1-7.

Larrubia Vargas, R., y Ocaña Ocaña, M.C., 2014, "Extranjeros en Andalucía: diversificación de las corrientes inmigratorias y sus patrones de distribución sobre el espacio andaluz”, en Revista Eria, núm. 93, págs. 101-119.

Leal Maldonado, J., 1994, “Cambio social y desigualdad espacial en el área metropolitana de Madrid (1986-1991)”, en Economía y Sociedad, núm. 10, págs. 61- 81. Consejerilla de Economía de la Comunidad de Madrid,

Leontidou, L., 2009, "Beyond the borders of Mediterranean Cities: the Mediterranean City in transition", in Quarterly of International Sociology, vol. 18, núm 3-4, págs.131-140.

Malheiros, J., 2002, "Ethni-cities: Residential Patterns in Northern European and Mediterranean Metropolises- Implications for Policy Design", in International Journal of Population Geography, 8, 107-134.

Maloutas, T. y Karadimitriou, N., 2001, "Vertical social differentiation in Athens: alternative or complement to community segregation?", in International Journal of Urban and Regional Research, vol. 25:4, págs. 699-716.

Maloutas, T., 1993, “Social segregation in Athens”, in Antipode, núm 25.3, págs. 223-39.

Martori i Cañas, J.C., 2004, "Indicadores cuantitativos de segregación residencial. El caso de la población inmigrante en Barcelona", en Scripta Nova. Revista 
electrónica de Geografía y Ciencias Sociales, vol. 7, núm. 169. Universidad de Barcelona. Disponible en http://www.ub.edu/geocrit/sn/sn-235.htm

Massey, D. and Denton, N., 1988, "Suburbanization and segregation in U.S. metropolitan areas", in American Journal of Sociology, núm. 94, págs. 592-626.

Ministerio de Fomento, 1991-2006, Análisis urbanístico de barrios vulnerables en España. Sobre la vulnerabilidad urbana. Instituto Juan de Herrera, disponible en http://www.fomento.gob.es/NR/rdonlyres/C88DB66D-8669-497C-BEE4442AE027E2FB/111287/SOBRE_vulnerabilidad.pdf

Musterd, S. and Deurloo, R., 2002, "Unstable Immigrant Concentration in Amsterdam: Spatial segregation and Integration of Newcomers", in Housing Studies, núm. 17, págs. 487-503.

Natera Rivas, J.J., 2012, "Población extranjera en el municipio de Málaga. Evolución de sus niveles de diferenciación residencial y se sus pautas de distribución espacial (2003-2010)" in Scripta Nova. Revista electrónica de Ciencias Sociales, vol. 16, núm. 413, Disponible en http://www.ub.edu/geocrit/sn/sn-235.htm

Natera Rivas, J.J. y Batista Zamora, A.E., 2012, "Impacto de la población extranjera en la evaluación y la estructura por edad de la población del municipio de Málaga” en Anales de Geografía, vol. 32, num. 2, págs. 323-344.

Natera Rivas, J.J., 2015, "Más dispersos pero más excluidos. Análisis de los niveles y evolución de la diferenciación y exclusión residenciales en Andalucía", en Estudios Geográficos, vol. 76, núm. 279. Pp. 609-632, doi: dx.doi.org/10.3989/ estgeogr.201522

Ocaña Ocaña, C., 1998, Áreas sociales urbanas. Observaciones sobre las ciudades andaluzas, serie Estudios y Ensayos, 21. Ed. Universidad de Málaga.

Openshaw, S., 1984, "The modifiable areal unit problem", en Concepts and techniques in modern Geography, núm. 38.

Reinoso Bellido, R., 2005, Topografias del paraíso. La construcción de la ciudad de Málaga entre 1897 y 1959. Ed. Colegio Oficial de Arquitectos de Málaga.

Rodríguez Vignoli, J, 2001, Segregación residencial socioeconómica: ¿qué es?, ¿cómo se mide?, ¿qué está pasando?, ¿importa?, CEPAL, Serie Población y desarrollo, núm. 16.

Sabatini, F., 1999, Tendencias de la segregación residencial urbana en Latinoamerica: reflexiones a partir del caso de Santiago de Chile. Universidad Católica de Chile.

Salvá Tomás, P. A., 2003, "La inmigración en Baleares: de un fenómeno tipo "Nueva Florida" a un modelo migratorio de "Nueva California"”, en Aubarell, G. (dir.), Perspectivas de la inmigración en España. Una aproximación desde el territorio. Icaria, Barcelona, págs. 129-154.

Sheyky, E. y Bell, W., 1955, Social area analysis, Standford University Press, California. 
Tecnocasa, 2013, Informe del Mercado de la vivienda. Análisis por precio y tipología. Málaga ciudad, primer semestre de 2013, Departamento de análisis e informes, Grupo Tecnocasa.

Vecina Merchante, C., 2013, "La acción comunitaria, un camino para la integración social y la interculturalidad", en Revista de Investigaciones en Intervención Social, vol. 3 (5), págs. 54-75.

White, M., 1983, "The measurements of spatial segregation", in American Journal of Sociology, núm, 88, págs. 1008-1018.

\section{RESUMEN CURRICULAR DE LOS AUTORES}

\section{Juan José Natera Rivas}

Licenciado en Geografía e Historia, especialidad Geografía, por la Universidad de Málaga. Doctor en Geografía con la calificación de Apto cum laude por unanimidad. Desde 2003 es Profesor Titular de Análisis Geográfico Regional, adscrito al Departamento de Geografía de la Universidad de Málaga, y desde 2015, miembro titular de FLACSO España. Ha dictado cursos de posgrado en diferentes Universidades argentinas, y ha publicado una veintena de trabajos sobre diferentes aspectos de la diferenciación residencial de la población urbana, tanto en el ámbito español como argentino. Dirección electrónica: jjnatera@uma.es

\section{Remedios Larrubia Vargas}

Doctora en Geografía por la Universidad de Málaga (2011). Profesora titular de Geografía Humana en la Universidad de Málaga, donde imparte docencia en las asignaturas de Fundamentos de Geografía Humana y desarrolla temas de investigación relacionados con la comercialización agraria, transformaciones recientes del espacio rural (desarrollo rural, mercado laboral transferencias sociales), agricultura ecológica, cultivos de vanguardia, innovaciones productivas; servicios del estado del bienestar (servicios sociales a la población, políticas sociales y estado del bienestar, turismo); población-inmigración. Entre las publicaciones más recientes cabe citar: en colaboración con Ocaña Ocaña M.C. "Extranjeros en Andalucía: diversificación de las corrientes inmigratorias y sus patrones de distribución sobre el espacio andaluz" en Revista Eria, 2014; núm. 93; "Residentes extranjeros y crecimiento demográfico en el territorio andaluz" en Boletín de la AGE. 2012, núm. 60. En colaboración con Ocaña Ocaña, M.C y Navarro Rodríguez, S.R. "Incidencia del senderismo en la economía local. Un análisis em- 
pírico a propósito del Parque Natural Sa de las Nieves" en Revista Anales de Geografía de la Universidad Complutense, 2013.

Dirección electrónica: rlarrubia@uma.es

Susana R. Navarro Rodríguez

Doctora en Geografía por la Universidad de Málaga y profesora titular en la Facultad de Filosofía, donde imparte docencia en los Grados de Historia y Geografía y Gestión del Territorio, y realiza labores de investigación sobre desarrollo en el medio rural, y cambios demográficos y flujos migratorios en Andalucía. Entre sus publicaciones más recientes aparece con Remedios Larrubia: "El desarrollo rural a través de las aportaciones científicas-académicas en revistas españolas (1990-2010)", en Anales de Geografía de la Universidad Complutense, vol. 1, 2011; con Carmen Ocaña y Remedios Larrubia: "Inmigración y dinámicas demográficas a comienzo del siglo XXI. Una perspectiva territorial”, en Revista de Estudios Geográficos, vol. 73, núm. 272, 2012 e "Incidencia del senderismo en la economía local. Un análisis empírico a propósito del Parque Natural Sa de las Nieves", en Revista Anales de Geografía de la Universidad Complutense, núm. 58, 2013. Dirección electrónica: susanros@uma.es

Artículo recibido el 29 de junio de 2015 y aprobado el 21 de mayo de 2016. 